Saudi Journal of Humanities and Social Sciences

Abbreviated Key Title: Saudi J Humanities Soc Sci

ISSN 2415-6256 (Print) | ISSN 2415-6248 (Online)

Scholars Middle East Publishers, Dubai, United Arab Emirates

Journal homepage: https://saudijournals.com/sjhss

Review Article

\title{
Study on Li Ziqi's Videos from the Perspective of Cross-Cultural Communication
}

\author{
Liu Qingxiang
}

College of Humanities and Social Sciences, Hei Longjiang Bayi Agricultural University, Da Qing, Hei longjiang, 163319, China

DOI: $10.36348 /$ sjhss.2020.v05i06.002 $\quad$ | Received: 01.06.2020 | Accepted: 08.06.2020 | Published: 11.06 .2020

*Corresponding author: Liu Qingxiang

\section{Abstract}

The paper discusses one of the most popular YouTube video bloggers (vlogger) Li Ziqi, and illustrates her popularity from the perspective of cross-cultural communication. It employs a framework for studying her cultural production on YouTube that focuses on its key components: cultural consciousness, harmony, and shared values between the modern China and the west. It demonstrates that filial piety, creativity, commitment, diligence and courage are still values in China, as well as the world. In addition, it explores the work of Fei Xiaotong and its implications for Li Ziqi's videos on YouTube, as well as Lao Tzu and Sun Tzu.

Keywords: Li Ziqi's Videos, cultural consciousness, harmony, shared values.

Copyright @ 2020: This is an open-access article distributed under the terms of the Creative Commons Attribution license which permits unrestricted use, distribution, and reproduction in any medium for non-commercial use (NonCommercial, or CC-BY-NC) provided the original author and source are credited.

\section{INTRODUCTION}

Cultural studies provide learners with insight into the target cultures, offering an opportunity to understand other countries, people and life styles without direct experience. People may become more tolerant of other cultures and less narrow-minded. Cultural studies may broaden people's horizons and develop their personality [1]. Li Ziqi is one of China's most successful vlogger for exporting traditional Chinese culture. With 20.77 million followers on Chinese social media platform Sina Weibo and 7.43 million subscribers on YouTube, she has made videos that appeal to netizens around the world [2]. Ms Li first blew up abroad in 2017 and gained internal traction on YouTube in 2019. Thanks to three months' overseas management, she has won a YouTube silver medal. Since then, she has successively served as "A representative of Chengdu intangible cultural heritage" and "A delegate leading the China rural youth to the prosperous life", and won the "annual cultural promotion Award". It is universally acknowledged that the girl is skillful in cooking and crafting in her videos, which is also the reason that she can win the popularity at home and abroad. The paper focuses on the three dimensional approach to studying her success and implications.

\section{Relationship between Shared Values and Her Aggressive Ambition}

"It is a complex process to realize cultural consciousness, which requires deep insight into self culture and responds to the changing environment ......., Establish universally accepted basic rules and inclusive cultural values" [3]. Xu Lixia, one Chinese video blogger who also uploaded videos of cooking Chinese food in a village on YouTube, told the Global Times that Li's videos are perfect in terms of filming and cooking. "Her contents are so diverse and really fascinating. She is living a life everyone dreams of," said Xu. Li knows what others need and want. It is well known that Chinese cuisine is an important part of the world. The preference for seasoning and cooking techniques of Chinese provinces depend on differences in historical background and ethnic groups. Li's hometown Sichuan cuisine has shaped its food customs with diverse and distinct ingredients. Characterized by its spiciness and pungency, Sichuan cuisine, prolific of tastes, emphasizes on the use of garlic and chili Peppers. Besides, Sichuan Hotpot, bacon and various snacks are most popular in China. The followers can enjoy the stories that relate to or build on their own experiences. Watching her videos is fun, relaxed activity for every one. Capacity... can be understood as the ability to solve problems and, equivalently, to make meanings by interpreting a particular instance(an event, and expression) as related to some formula, thereby assimilating the instance into a pre-existing pattern of 
knowledge, or, when necessary, by modifying the available formulae so that the instance can be accommodated with them [4].

Unlike many other food bloggers, Li's videos set China's countryside as the stage and start with how the foods are planted and harvested in the farm. She rarely speaks in the process. Plus, CCTV praised her and stated "Without a word commending China, Li promotes Chinese culture in a good way and tells a good China story." Speak highly of China with actions instead of words. The study suggests that the audiences to Li's videos can see positive energy. Although all cultures are diversified, human beings share something in common. Ancient Chinese, just like American settlers, had to depend on their own hands in doing everything in order to survive in the constant struggle against nature. The older generations of China still lived a kind of self-sufficient life, which had great influence on Ms. Li.

Chinese values are deeply influenced by Confucianism. Only when one's self-cultivation reaches to a certain level can he set an example to his family. She had aggressive ambition though working as a seemingly tiresome farmer everyday. Making a deep impression on everyone, Li has changed the stereotyped countryside, where are supposed to be ugly and stinky. "Her garden is the most beautiful one that I have ever seen." said one follower. People can easily buy worksaving devices and ready-made products such as soy sauce in stores and supermarkets, but she chooses to make the condiment herself, starting from planting the soy bean in the earth. From food to furniture and cosmetics, Li has shocked netizens with what she can do and how she does it. "She is my favorite YouTuber, chef, artist, gardener," a subscriber called Corazon Cestona commented. "Her videos don't have much rhetoric, but show the beauty of Chinese culture gently and vividly, which is much better than some propaganda-style discourse in traditional cultures products," said one Chinese netizen. One of her videos introducing Chinese paper-making that originated during the Han Dynasty has been viewed 7.07 million times on YouTube. As Sun Tzu said, if you know yourself and your enemy then you can always win, if you know only yourself then you may win or lose, if you know neither yourself nor your enemy then you will most likely lose. Chinese culture is inclusive, as demonstrated in the attitudes of Confucianism towards Buddhism. Anyone with a good command of Chinese history will appreciate the inclusiveness of its culture and better understand China of today.

YouTube has maintained a public tag-line, meant to be read as an "Broadcast youself". These two words lay bare the way YouTube's operators hope to construct their site in the public imagination, that YouTube is a space to create, to consume, and to share [5]. She is capable of creating everything with her own two hands, from dying a dress with fresh grape juice, to fashioning traditional lipsticks from roses in her garden, to making a bamboo fence, to brewing beer with measuring cups, to preparing Chinese Cuisine from one after another. "No wonder she performs the work of a farmer with the grace of a fairy, impressing with her deep knowledge of food, nature and Chinese culture" [6].

\section{Associations between Hunting for "Root" and Affections for Her Home}

People have "self-knowledge" of their own culture. The purpose of self-knowledge is to strengthen the independent ability of cultural transformation, adapting to the new environment in the new era......It denies "Fugu", complete "westernization" or total "Otherization". Those are cited from Fei [3].

Miss Li lived in a rural village of Sichan Province in Southeast China. Li was orphaned at her early age and brought up by her grandparents. At 14, she dropped out of school and went to hunt for the job in the big city. When her grandfather died, she moved back to take care of her grandmother. As Chinese saying goes "Filial piety comes first". For most of Chinese, the family and the community themselves were the source of personal and shared values. Chinese society's strict expectations of its members kept the Chinese in line in some degree as well. I believe that many foreigners are finding themselves lost in the ideas of individualism. The East and the West have always had differing sources of morals and values. Religion has always been the dominating source of community values and morals in the Western world. Li told Xinhua in an interview. "When I worked in the city, it was about survival. Now when I was lived in the countryside, I feel like I'm living." Chinese online star Li Ziqi provides an escape from urban life.Li's YouTube videos center on her life with her grandmother in the rural parts of Sichuan Province, which shows respecting the old is one of most important traditional virtues. Contrary to the west, China put emphasis on the aged and cared more about them since they are full of wisdom and experience. As Chinese saying goes, "The old ginger is hotter than the new one". By contrast, American society often deprives the aged of import and psychological forms of support--a feeling of being respected, wanted and needed.

In the videos, $\mathrm{Li}$ often rises at sunrise, rests at sunset, plants seeds and harvests flowers, cooks Chinese dishes and crafts bamboo furniture. No one doubted her creativity, her industry or her intelligence. Cultural consciousness is based on the search and inheritance of "root". She even spent a few months exploring how four treasures of the study, that is, brush, ink stick, paper, ink stone came into being. The video titled by Traditional handicraft: Turn a Soybean seed into a drop of soy sauce also makes a deep impression on me. She even raised baby ducklings just to make a 
sauce out of salted duck eggs. According to China Daily, Without passion, is there no Li Ziqi. Without passion, you can't understand Ms. Li. The audience to her videos have perceived passion from her and that explained why she was an internet influencer.

She is fond of loose Hanfu-inspired linen clothing, which was formed during Han Dynasty based on the Four Books and Five classics. Circular-cut long sleeves represent "heaven", displaying a sense of graceful generosity and elegant movement. Cross collars represent "earth", which conducted people to follow discipline [7]. There is no denying that it has passed away long long time ago. However, she makes us realize how beautiful one kind of ancient clothes is.

\section{Harmony and Peaceful Music}

What appeals to so many audiences is music. We can hear peaceful music from her videos. A snowy mountain, A poem of rain, Weaving a dream, Early summer and so on.She has a good heart to lean on. What she intends to do is to make people relaxed since it is no use worrying about things that you can't change, In today's society, many people work under pressure and feel exhausted and tired in their daily life. "When you watch my videos at the end of a busy day. I want them to relax and experience something nice, Try to take away some of their anxiety and stress" It is Harmony that is an important idea in traditional Chinese values. Chinese people emphasize harmony when dealing with people and things. Lao Tzu focuses on that what is perceived to be the undeniable fact that human attempts to make the world better actually make the world worse. Therefore, it is better to strive for harmony, minimizing potentially harmful interference with nature or in human affairs [8]. She pursue the selfsufficient lifestyle of Chinese people about 40 years ago. At that time, people ate organic vegetables without toxic pesticide. In addition, clothes and most food were made by hand. People respect nature and live harmoniously with it. In an interview with Goldthread in September 2019, Li stated "I simply want people in the city to know where their food come from."

Li appears to have an ancient agricultural life while living in modern times. Tilling farm land and spinning and weaving were two major features of Chinese agricultural society in ancient times. The dependence on nature nurtures Chinese people's affection for natural scenery and promotes the philosophy of living peacefully with nature [9]. Meanwhile, She also use the platform to produce versions of pastoral life that are increasingly sophisticated, consistent, and customizable. She reveals YouTube as a valuable site for cultural practice, which should continue to be both accessible and open to creative possibility for some time to come. Global audiences have expressed their love for her videos and admiration for her rural life. Many have started describing her as a spokesperson for the Chinese pastoral lifestyle and use her videos for "relaxation therapy." Most Chinese people are characteristic of peace, reserve and modesty. They are very kind, and would like to help others whenever any one is in trouble. $\mathrm{Li}$ is an idealized image and makes it possible for people to be quiet and peaceful when protesting against the world. "No matter how I need and enjoy technology, This is what kind of life I'm dreaming of. Without debts, without trouble, without expect, relieve your eyes. There is no social standard and it is only a peaceful life." one video watcher said.

"It's convinced that audiences are absorbing useful information from Ms. Li about how to live off the land.The videos are deeply soothing. But it's not just that - they reveal the intricacy and intensity of labor that goes into every single component of every single dish, while also making the long, solitary processes of producing food seem meaningful and worthwhile" [10]. The statement above suggested that overseas audiences like her videos very much.

However, There is a hot debate whether the videos were always filmed in villages and catered to what critics characterized as Western stereotypes of a backward China. Her videos indeed set us thinking. Ancient culture is not backward, on the contrary, embodying of high civilization. Nowadays, people at home and abroad are tired of high technology, skyscrapers, fast food, ready-made products and so on. For example, Transportation and services are convenient and cheap in China. You don't need to learn driving because there are so many options, taxi, Didi App (one kind of service for reserving the car). So we want to live in a different world just like Li's bucolic world where we can enjoy DIY and a self-sufficient life.

It is concluded that this paper analyzes $\mathrm{Li}$ Ziqi's popularity from the perspective of cultural value of SunTzu and Lao Tzu based on Fei Xiaotong's "cultural consciousness", building a discourse system with Chinese characteristics, Chinese style and Chinese ways of thinking. So it would be wise to take an active role in refining and publicizing the resonance of shared values among human beings. The popularity of "Li Ziqi phenomenon" constantly encourages us to think about how to promote Chinese positive energy faster and better. We need mutual communications since the world is becoming gradually globalizing. There will be more chances to know each other and to learn from each other. Therefore, we should respect different cultures and values and at the same time try to retain our own. It is a top priority to establish universally accepted basic rules and inclusive cultural values.

\section{REFERENCES}

1. Chengdong, X. (2003). Developing Learners' Cultural Capacity in TEFL [J]. Teaching English in China, (3):96-99 
2. Chinese Netizens are Celebrating Vlogger Like $\mathrm{Zi}$ qi'sMajor YouTube Milestone [N]. RADII, Feb.3, https://radiichina.com/li-ziqi-youtube-milestone/

3. Xiaotong, F.(1997). Reflection, Dialogue and Cultural Consciousness [J]. Pecking University, (3):15-17.

4. Widdowson, H. G. (1983). Learnign Purpose and Language Use. Oxford: Oxford University Press.

5. Lashley, M. C. (2013). Making culture on YouTube: Case studies of cultural production on the popular web platform (Doctoral dissertation, University of Georgia).
6. Ashley, D. (2018). Chinese food vlogger cooks up YouTube storm $[\mathrm{N}]$. The Straits Times.

7. Xiaoli,S. (2018). Comparison between Chinese and Western Culture [M], FuDan University Press, 145.

8. Rongpei,W. (2018). 21 st century College English [M], FuDan College Press, 229.

9. Jing,G. (2020). Vlogger sparks debate on culture promotion $[\mathrm{N}]$, The Global Times.

10. Tejer, L. (2020). The reclusive food celebrity Li Ziqi is my quarantine queen [N]. The New York Times. 